\title{
Lethal congenital contracture syndrome type 1
}

INSERM

\section{Source}

INSERM. (1999). Orphanet: an online rare disease and orphan drug data base. Lethal congenital contracture syndrome type 1. ORPHA:1486

Lethal congenital contracture syndrome type 1 is a rare, genetic arthrogryposis syndrome characterized by total fetal akinesia (detectable since the 13th week of gestation) accompanied by hydrops, microg nathia, pulmonary hypoplasia, pterygia and multiple joint contractures (usually flexion contractures in the elbows and extension in the knees), leading invariably to death before the 32 nd week of gestation. Lack of anterior horn motoneurons, severe atrophy of the ventral spinal cord and severe skeletal muscle hypoplasia are characteristic neuropathological findings, with no evidence of other organ structural anomalies. 